\title{
Original Article: \\ HIV seropositivity and its ethical implications for blood donors in a tertiary care hospital of Andhra Pradesh
}

\author{
I.S. Chaitanya Kumar, K.V. Sreedhar Babu, A. Yashovardhan, D. S.Jothi Bai \\ Department of Immuno Haematology and Blood Transfusion, \\ Sri Venkateswara Institute of Medical Sciences, Tirupati.
}

\begin{abstract}
Background: Blood is a scarce, but lifesaving resource; it is also the most efficient vehicle for the transmission of human immunodeficiency virus (HIV). Hence there is a need for accurate screening of HIV among blood donors. The present study was designed to assess the seroprevalence of HIV, among the blood donors in a tertiary care hospital, Andhra Pradesh.

Methods: Prospective study over a period of one year. A total of 5,329 donor blood samples were screened for HIV status using enzyme linked immunosorbent assay. The reactive samples have been tested again twice using different kits. The samples reactive all three times were considered positive. The samples which were positive only in first test were labelled as false positive.

Results: Out of 5,329 blood donors screened, $27(0.5 \%)$ were initially reactive and $15(0.28 \%)$ were reactive after triple testing.

Conclusions: Our study showed similar HIV seroprevalence as that reported by National acquired immunodeficiency syndrome control organization statistics. But there was a mild increase in HIV prevalence among rural donors in our region compared to the urban donors.
\end{abstract}

Key words: Human immunodeficiency virus, Seroprevalence, Voluntary blood donors

Chaitanya Kumar IS, Sreedhar Babu KV, Yashovardhan A, Jothi Bai S. · HIV seropositivity and its ethical implications in blood donors in a tertiary care hospital of Andhra Pradesh. J Clin Sci Res 2012;1:8-14.

\section{INTRODUCTION}

Blood is a scarce, but life saving resource; however, blood transfusion can be a source of life threatening infections, if screening is not carried out properly. ${ }^{1}$ As per National Acquired immunodeficiency syndrome Control Organisation (NACO), the prevalence of human immuno deficiency virus (HIV) infection in adults in India is $0.29 \%{ }^{2}$ There are many reports about the HIV prevalence among blood donors in India, the rate ranging between $0.084 \%$ to $3.87 \%{ }^{3}$ -9 and sparse data are available on this topic from Andhra Pradesh. Hence this study was conducted to assess the seroprevalence of HIV among the voluntary and replacement blood donors at a tertiary care teaching hospital, in Tirupati, Andhra Pradesh. Also, this study aims at studying the basic demographic profile (age, sex, urban/rural status) of seropositive blood donors and to analyse the ethical challenges involved in HIV testing.

\section{MATERIAL AND METHODS}

This prospective study was carried out over a period of one year, from $1^{\text {st }}$ March 2010 to $28^{\text {th }}$ February 2011 in the Department of Immuno Haematology and Blood Transfusion at a tertiary care teaching hospital, at Tirupati, Andhra Pradesh.

The donors were accepted for blood donation after the selection procedures as per NACO guidelines after getting a written informed consent. The demographic details like donor's age, sex, rural/urban status, type of blood donation and history of past donation were recorded. were recorded. A total of 5,329 donor blood samples were screened by Central Drug Standard Control Organization (CDSCO) approved enzyme linked immuno-sorbent assay (ELISA) kit (Vironostika HIV Ag/ $\mathrm{Ab}-4^{\text {th }}$ generation ELISA test, BioMerieux bv, The Netherlands). It is based on one-step "sandwich ELISA principle". If HIV-1 p24 antigens, anti HIV-1, anti HIV-2, anti HIV-1 group $\mathrm{O}$ antibodies

Received: 22 December, 2011

Corresponding author: Dr I.S. Chaitanya Kumar Department of Transfusion Medicine, Sri Venkateswara Institute of Medical Sciences, Tirupati 517507, India. e-mail: chaitanyakumar_is@ yahoo.co.in 
were present in human serum/ plasma, an intense yellow colour develops in the well at the end of procedure. If the sample is free from the above mentioned antigen/ antibodies, no colour is formed.

The blood units, which were found to be seroreactive were discarded as per National biomedical waste management policies. The samples which were reactive in the first assay were further tested independently by different kits (Genscreen ${ }^{\mathrm{TM}}$ Ultra HIV Ag$\mathrm{Ab}$, Biorad, France or Enzaids HIV-1+2 Elisa test kit, Span Diagnostics, India and HIV Tri-dot, Diagnostic Enterprises, India) as a departmental policy. Any sample, reactive in the first ELISA test, but with nonreactive results in later tests using two different kits were considered false positive. Any sample reactive in the first ELISA test and has repeatable reactivity in at least one kit was considered positive.

Test kits were chosen in such a way that, all samples will be screened at least once with a $4^{\text {th }}$ generation ELISA kit for detection of HIV-1 and 2. Manufacturer's instructions were followed scrupulously while performing each assay. All the donors who had a reactive result were referred to the ICTC for counselling and confirmation. For comparison of HIV seroreactivity during the study period with previous years, data pertaining to HIV seroreactivity of past years that was available from blood bank records was used.

\section{Statistical analysis}

The various variables studied included age, sex, urban/rural status, type of donation (voluntary or replacement) and seroreactive status for HIV. Descriptive statistics for categorical variables were performed. The association between two categorical variables was evaluated by Chi-square test or Fisher's exact test whichever is appropriate using WinPepi software, (Windows statistical analysis software for Epidemiologists, Version 11.8.) or Graph Pad QuickCalcs online calculator for scientists respectively. For all statistical tests performed, a P-value of less than 0.05 was considered significant.

\section{RESULTS}

The variations with respect to sex, type of donation and region among the donors is presented in Table 1 . The age distribution and the significance is presented in Table 2. The effect of single and triple testing and prevalence of seropositivity over the last three years is presented in Tables 3 and 4 . Out of the 5,329 blood donations screened,

$27(0.50 \%)$ were found to be seroreactive for HIV in the first assay. When the reactive samples were further tested by the second ELISA and rapid (immunochromatographic) tests, $15(0.28 \%)$ were found repeat reactive (seropositive as per NACO criteria) and $12(0.22 \%)$ samples were negative. On repeat testing we were able to eliminate the false positives which accounted for $44.4 \%$ of all HIV reactive in first ELISA.

Of the 15 seropositive blood donations, 14 $(93.3 \%)$ were from males. We found no statistically significant difference between the prevalence of HIV among males and females $(\mathrm{p}=0.461)$. Among the triple reactive donors, four $(26.67 \%)$ were voluntary and $11 \quad(73.33 \%)$ were replacement. There was no statistically significant difference between HIV seroreactivity among the voluntary and replacement donors $(\mathrm{p}=0.446)$. Of the 15 seropositive donors, seven were from urban areas $(46.67 \%)$. There was no statistically significant difference between the donors of rural and urban areas as to HIV seroprevalence $(\mathrm{p}=0.176) ; 12(80 \%)$ of the seropositive donors were repeat donors and have donated earlier in other blood banks and their interval from last donation ranged from six months to seven years. Among seropositive donors, $11(73.33 \%)$ were in the age group of 21-30 years, two each in the age groups of $31-40$ and $41-50$ years. Though most donors are in the age group of 21-30, we found no statistically significant difference between the categorised age groups and HIV prevalence $(\mathrm{p}=0.389)$. Twelve $(0.22 \%)$ false seroreac- 
tive samples were detected after triple testing, but there was no statistically significant difference between single and triple testing and detection of HIV. The HIV seroreactive donors have declined over the years and there is a statistically significant decline in HIV seroreactive rate even without triple testing.

\section{DISCUSSION}

Currently the safety of blood for transfusion is ensured by careful selection of donors and mandatory screening for transfusion transmissible infections (TTI). Despite these measures, occasional transmission of HIV via blood transfusion has been reported. This can occur due to window period donations or due to a breakdown in good manufacturing practice.

The primary purpose of screening donor blood for infectious disease markers is to prevent pathogen transmission to the recipients. However blood transfusion services on the other hand also have a "duty of care" to donors with respect to adverse test results. Failure to discharge this responsibility with due care can have serious consequences like negative impact on public confidence towards transfusion services. ${ }^{10}$

In other countries, HIV seroprevalence among healthy blood donors ranged from $11.7 \%$ in Ethiopia ${ }^{11-15}$ to $0 \%$ in Saudi Arabia. ${ }^{16,17}$ Again it varies with population group under study, education and awareness levels in those particular countries. In our study it is $0.28 \%$ after repeat testing. This is similar to the published NACO estimate of $0.29 \% .^{2}$ There are Indian studies reporting HIV seropositivity rate among blood donors varying around $0.072 \%$ using ELISA and western blot and $0.55 \%$ using ELISA alone. In one study ${ }^{9}$ the true seropositivity has been assessed in three stages using two different ELISA kits and western blot among the blood donors. They found a HIV seroreactivity of $1.28 \%, 0.11 \%$ and $0.028 \%$ at the three stages respectively. ${ }^{9}$ There is a similar decline in HIV seropositivity on repeat testing with multiple kits in our study. There are HIV seroprevalence reports pertaining to the blood donor population from the adjoining states of Tamilnadu $^{18}$ and Karnataka ${ }^{19,20}$ which showed a HIV seroprevalence of $0.13 \%$ $0.38 \%$ and $0.44 \%-0.81 \%$ respectively. This heterogeneity in prevalence of HIV seroreactivity in South India may be related to demographic and socioeconomic differences between these places. The prevalence of HIV seropositivity among male donors is $0.27 \%$ and that among female donors is $0.46 \%$ (Table 1). This high prevalence of seropositivity among female blood donors may be attributed to the smaller number of female blood donors who donated blood at our centre and was found statistically not significant.

The prevalence of HIV seropositivity among voluntary blood donors is $0.21 \%$ and that among replacement donors is $0.32 \%$ (Table 1 ). This shows a 1.5 times higher prevalence of HIV seropositivity among replacement donors compared to voluntary blood donors. Though this may not be statistically significant, it suggests the need for improving voluntary blood donation among all blood banks. A similar slightly higher prevalence of HIV among replacement donors has been documented in other studies. ${ }^{4,6,7}$ In another study, a higher prevalence of HIV seropositivity has been documented among voluntary blood donors also. ${ }^{21}$ This suggests that, there is a high degree of variability of HIV seroreactivity among voluntary and replacement donors of different geographic locales.

The prevalence of HIV seropositivity among blood donors from urban areas was found to be $0.21 \%$ only, while that from rural areas was $0.41 \%$ (Table 1). Though this is statistically not significant, we found a two times higher prevalence of HIV among blood donors from rural areas. This could be probably due to better health education, awareness and socioeconomic status at urban areas. This is in contrast to the National Family Health Survey 20052006 HIV statistics which found a HIV seropositivity of $0.35 \%$ in urban areas and $0.25 \%$ in rural areas among general adult population of India. 
Most of the HIV seroreactive blood donors, in our study (11 out of 15) belonged to the age group 21-30 years (Table 2). But again, the highest prevalence of HIV seroreactive blood donors among the different age groups was seen between $41-50$ years (0.68\%, i.e., two out of 290 donations found positive).

The seropositivity of HIV $(0.28 \%)$ is much less compared to the seroreactivity of HIV $(0.50 \%)$ (Table 3$)$. By repeating the test using different kits, elimination of biological false reactives and technical errors occurred. Over the years, there has been a steady decline in the prevalence of HIV seroreactivity from $1.56 \%$ in 2008 2009 to $0.50 \%$ in $2010-2011$ when tested using one time ELISA. There has been a statistically significant decline in the prevalence of HIV seroreactivity during 2010-2011 when compared to statistical data from previous years 2008-2009 and 2009-2010 (Table 4).

This decline in HIV seroreactivity could be because of, not only a change in the generation of ELISA kits used for HIV detection from third generation to fourth generation, but also the result of multiple HIV awareness campaigns, improved blood donation rate. western blot instead of a second ELISA, the chance of detecting truly positive is presumed to increase to $99.98 \%$. $^{22}$ While we can label blood as safe after HIV testing, it is risky to label any donor as HIV positive with a single test result and the authorities of the blood transfusion service must be aware of the interpretation of the test. ${ }^{22}$

According to the action plan for blood safety, all the HIV reactive blood donors should be notified of their TTI status if they have consented to know the same at the time of donation. In under resourced countries like India, confirmatory test using nucleic acid amplification techniques (NAT) on HIV seroreactive blood may not be feasible.

In such circumstances, the $4^{\text {th }}$ generation ELISA methods, using combined antigen/antibody detection kits are a better alternative with improved specificity. Along with NAT for donor screening, vigilance of errors while performing the screening test, other factors such as public awareness, educational and motivational programmes help in decreasing the infection. ${ }^{23}$ Similarly the maximum benefit will come not from using expensive new technology but from quality assurance and better use of proven serological tests. ${ }^{24}$ Donors come to the blood bank with altruistic intensions. Reactive results in screening tests, not only trigger the loss of blood units, but also trigger the placement of donor on a deferral registry for notification and counselling. Nonreproducible test results related to a transient event may present problems. Though, blood centre is not responsible to act as a primary health care provider, it is clearly the ethical responsibility of the blood centre to provide correct information to the donor regarding current health status through the tests performed on the donated blood. In the past, disclosure by blood banks regarding TTI status has resulted in serious consequences for some donors. ${ }^{25}$ However given the high cost of neglecting to notify

Table 1: Distribution of HIV seropositivity among various groups*

\begin{tabular}{lllll}
\hline Variable & Seropositive No. $(\%)$ & Seronegative No. $(\%)$ & Total No. $(\%)$ & p-value \\
\hline Male & $14(0.26)$ & $5,100(95.70)$ & $5,114(95.96)$ & \\
Female & $1(0.02)$ & $214(4.02)$ & $215(4.04)$ & 0.461 \\
Voluntary & $4(0.08)$ & $1,920(36.03)$ & $1,924(36.11)$ & \\
Replacement & $11(0.20)$ & $3,394(63.69)$ & $3,405(63.89)$ & 0.446 \\
Rural & $8(0.15)$ & $1,939(36.39)$ & $1,947(36.54)$ & \\
Urban & $7(0.13)$ & $3,375(63.33)$ & $3,382(63.46)$ & 0.176
\end{tabular}


Table 2: Prevalence of HIV among different age groups

\begin{tabular}{llll}
\hline Age group (years) & $\begin{array}{l}\text { Seropositive } \\
\text { No. }(\%)\end{array}$ & $\begin{array}{l}\text { Seronegative } \\
\text { No. }(\%)\end{array}$ & p-value \\
\hline $18-20$ & $0(0)$ & $582(10.92)$ & 0.3964 \\
$21-30$ & $11(0.21)$ & $3,327(62.43)$ & 0.4390 \\
$31-40$ & $2(0.04)$ & $1,035(19.42)$ & 0.5111 \\
$41-50$ & $2(0.04)$ & $290(5.44)$ & 0.1970 \\
$51-60$ & $0(0)$ & $80(1.50)$ & 1.0000 \\
& & &
\end{tabular}

HIV=human immunodeficiency virus

Table 3: Comparison between HIV reactivity by single/triple testing of donor samples during2010-2011

\begin{tabular}{llll}
\hline Year & $\begin{array}{l}\text { Total donors screened } \\
\text { No. }(\%)\end{array}$ & $\begin{array}{l}\text { Total HIV reactive } \\
\text { No. }(\%)\end{array}$ & p-value \\
\hline $\begin{array}{l}2010-2011 \\
\text { (Single testing) }\end{array}$ & 5,329 & $27(0.50 \%)$ & 0.064 \\
& & & \\
$\begin{array}{l}2010-2011 \\
\text { (Triple testing) }\end{array}$ & 5,329 & $15(0.28 \%)$ & 1.000
\end{tabular}

HIV=human immunodeficiency virus

Table 4: Comparison between HIV reactivity over the years 2008-2011

\begin{tabular}{llll}
\hline Year & $\begin{array}{l}\text { Total donors } \\
\text { screened }\end{array}$ & $\begin{array}{l}\text { Total HIV reactive } \\
\text { No. }(\%)\end{array}$ & p-value \\
\hline $2008-2009 *$ & 6,010 & $94(1.56)$ & 0.000 \\
$2009-2010^{*}$ & 5,289 & $45(0.85)$ & 0.031 \\
$2010-2011 \dagger$ & 5,329 & $27(0.50)$ & 1.000
\end{tabular}

$* 3^{\text {rd }}$ generation ELISA kits used for HIV screening; $\uparrow 4^{\text {th }}$ generation ELISA kits used for HIV screening $\mathrm{HIV}=$ human immunodeficiency virus; ELISA= enzyme linked immunosorbent assay

infected donors, it is recommended to disclose the results of TTI testing directly to the donor by a counsellor after proper counselling at an ICTC centre.

The present study adds to the data pertaining to HIV seroprevalence among blood donors, especially in Rayalaseema region of Andhra Pradesh, a state which has the second highest prevalence of HIV in the general population of India. ${ }^{26}$ The present study $(0.28 \%$ HIV seropositivity) gave compara- ble results with that of NACO statistics (0.29\% HIV seropositivity). ${ }^{2}$ There was a slightly higher HIV seropositivity in donors coming from rural areas. There is a steady decline in HIV seroreactivity among blood donors over the past three years in this region. HIV infection has tremendous psychological impact on Indian society. The stigma of being informed about HIV positive status creates personal and family stress. 
Hence our study suggests that HIV seropositivity be assessed by sequential immune assays prior to the referral of the donor to ICTC/ permanent deferral of a repeat donor.

\section{REFERENCES}

1. Dodd RY. Infectious disease testing. In: Hillyer CD, Silberstein LE, Ness PM, Anderson KC, editors. Blood banking and transfusion medicine basic principles and practice. 1st edition. Edinburgh: Churchill Livingstone; 2003.

2. Annual report 2009-2010. National AIDS Control Organization, Department of AIDS Control, Ministry of Health and Family Welfare, Government of India. New Delhi: National AIDS Control Organization .p.4-6.

3. Gupta N, Kumar V, Kaur A. Seroprevalence of HIV, HBV, HCV and syphilis in voluntary blood donors. Indian $\mathbf{J}$ Med Sci 2004;58:3067.

4. Singh B, Kataria SP, Gupta, R. Infectious markers in blood donors of East Delhi: prevalence and trends. Indian $\mathbf{J}$ Pathol Microbiol 2004;47:477-9.

5. Nanu A, Sharma SP, Chatterjee K, Jyoti P. Markers for transfusion-transmissible infection in north Indian voluntary and replacement blood donors: prevalence and trends 1989-1996. Vox Sang 1997;73:703.

6. Makroo RN, Salil P, Vashist RP, Lal S. Trends of HIV infection in blood donors of Delhi. Indian J Pathol Microbiol 1996;39:13942.

7. Chattoraj A, Behl R, Kataria VK. Infectious disease markers in Blood Donors. MJAFI 2008;64:33-5.

8. Shukla RS, Bhuyan KK. Can data on HIV Sero-reactivity among blood donors provide an insight into HIV prevalence in the general population? Indian J Public Health 2007;51:14-9.

9. Choudhury N, Ayagiri A, Ray VL. True HIV Seroprevalence in Indian blood donors. Transfus Med 2000;10 1-4.

10. Busch, M. P., To thy (reactive) donors be true! Transfusion 1997;37:117-20.

11. Dessie A, Abera B, Wale F. Seroprevalence of major blood-borne infections among blood donors at Felege Hiwot referral hospital, northwest Ethiopia. Ethiop J Health Dev 2007;21:68-9.

12. Moore A, Herrera G, Nyamongo J, Lackritz E, Granade T, Nahlen B, et al. Estimated risk of HIV transmission by blood transfusion in Kenya. Lancet 2001;358:65760.
13. Sentgens R, Sisay Y, Vrielink H, Kebede D, Aber HJ, Leckie G, et al. Prevalence of and risk factors for HIV infection in blood donors and various population subgroups in Ethiopia. Epidemiol Infect 2002;128:221-8. 14. Afsar I, Gungor S, Sener AG, Yurtsever SG. The prevalence of HBV, HCV and HIV infections among blood donors in Izmir, Turkey. Indian J Med Micro- biol 2008;26:288-9.

15. Butsashvili M, Tsertsvadze T, McNutt LA, Kam- kamidze G, Gvetadze R, Badridze N. Prevalence of hepatitis B, hepatitis C, syphilis and HIV in Geor- gian blood donors. Eur $\mathrm{J}$ Epidemiol 2001;17:693-5.

16. El-Hazmi MM. Prevalence of HBV, HCV, HIV-1,2 and HTLV-I/II infections among blood donors in a teaching hospital in the Central region of Saudi Arabia. Saudi Med J 2004;25:26-33.

17. Khan MA, Rehman A, Ashraf M, Ashraf M, Ali A, Ditta A. Prevalence of HBV, HCV and HIV in blood donors at Liaquetpur. Professional Med J 2006;13:23-6.

18. Rose D, Sudarsanam A, Padankatti T, Babu PG, John TJ. Increasing prevalence of HIV antibody among blood donors monitored over 9 years in one blood bank. Indian J Med Res 1998;108:42-4.

19. Sonth SB, Solabannavar SS, Baragundi MC, Patil CS. The prevalence of HIV-2 seropositivity in blood donors. Journal of Clinical and Diagnostic Research 2010;4:3091-4.

20. Pallavi P, Ganesh CK, Jayashree K, Manjunath GV. Seroprevalence and trends in transfusion transmitted infections among blood donors in a university hospital blood bank: A 5 year study. Indian J Hematol Blood Transfus 2011;27:1-6.

21. Adhikari L, Bhatta D, Tsering DC, Sharma DK, Pal R, Gupta A. Infectious disease markers in blood donors at Central Referral Hospital, Gangtok, Sik- kim. Asian J Transfus Sci 2010;4:41-2.

22. Crowe D. Concerns about HIV/AIDS testing and management 2001. Available at URL: http:// www.virusmyth.com/aids/hiv/ dctest.ht.

23. Pahuja S, Sharma M, Baitha B, Jain M. Prevalence and trends of markers of hepatitis C virus, hepatitis $B$ virus and human immunodeficiency virus in Delhi blood donors. a hospital based study. Jpn J Inf Dis 2007;60:389-91. 
24. Mortimer PP. Ten years of laboratory diagnosis of HIV: how accurate is it now? J Antimicrob Chemother 1996;37(Suppl B):2732.

25. Choudhury LP, Tetali S. Ethical challenges in voluntary blood donation in Kerala, India. J
Med Ethics 2007;33:140-2.

26. NACO Annual Report 2010-11. National AIDS Control Organization. Ministry of Health and Family Welfare, Government of India. Available at URL: http://www.nacoonline.org. Accessed on 21 Dec 2011. 